\title{
Electrode-Induced Nonuniformities in the Sweeping of Alpha Quartz
}

\author{
J. G. Gualtieri, Senior Member, IEEE and J. A. Kosinski, Member, IEEE
}

\begin{abstract}
Electrode metal-quartz contact, metal porosity, and metal/quartz interfacial diffusion of hydrogen-species are required for efficient and uniform hydrogen introduction during air-sweeping. Nonuniform hydrogen introduction can be indicated by the cointroduction of either electrode-metal or color centers. Color-center introduction during air sweeping leads to nonuniform sweeping along the $Z$-axis similar to the nonuniform sweeping found with vacuum sweeping. Using infrared absorption and scanning electron microscopic techniques, it has been found that color-center and/or electrodemetal introduction into quartz is influenced by the porosity of evaporated metal electrodes. It appears that thermal-stress relief of electrode-metal films, during sweeping, normally causes void formation (porosity). If the porosity is extensive, $\mathrm{H}$ introduction predominates and color-center and electrode-metal introduction mechanisms are suppresed. Samples swept with evaporated $\mathrm{Au}-\mathrm{Cr}$ electrodes relying on thermal stress-induced porosity sometimes displayed these sweeping nonuniformities. However, nonuniformities were not found when samples were swept using evaporated $\mathrm{Au}-\mathrm{Cr}$ electrodes containing periodic stripe openings. Electrodes with stripe openings were fabricated using photolithographic techniques. The stripe openings provided sufficient electrode-quartz-water vapor (three-phase) regions to ensure uniform sweeping. Cniform sweeping was also obtained using magnetron-sputtered amorphous $\mathrm{Y}-\mathrm{Ba}-\mathrm{Cu}-\mathrm{O}$ films. These electrically conducting oxide films apparently allow indiffusion of hydrogen without the need of porosity or electrode openings to assist in the $\mathbf{H}$ indiffusion sweeping process.
\end{abstract}

\section{INTRODLCTION}

$I^{\mathrm{T}}$ T IS WELL KNOWN that the sweeping of quartz not only results in an improvement in mechanical $Q$, but also improves quartz resonator stability in a radiation environment and reduces the etch-channel density of etchprocessed quartz [1], [2]. Previous investigators have indicated that vacuum sweeping can be nonuniform and the use of resonators processed in this maner may lead to unpredictable results [3].

Nonuniform air-sweeping of quartz is associated with the nonporosity of evaporated metal electrodes [4]. That is, openings in the metallization are required when hydrogen diffusion through the metal electrode is too slow. The nonuniformity along the $Z$-axis (see Fig. 1 and [5, Figs. 9 and 10]) is associated with the development of color

Manuscript received December, 10, 1990; revised April 26, 1991; accepted May 3, 1991

The authors are with USA ETDL. SLCET-MA-A. Fort Monmouth, NJ 07703-5601

IEEE Log Number 9101519.

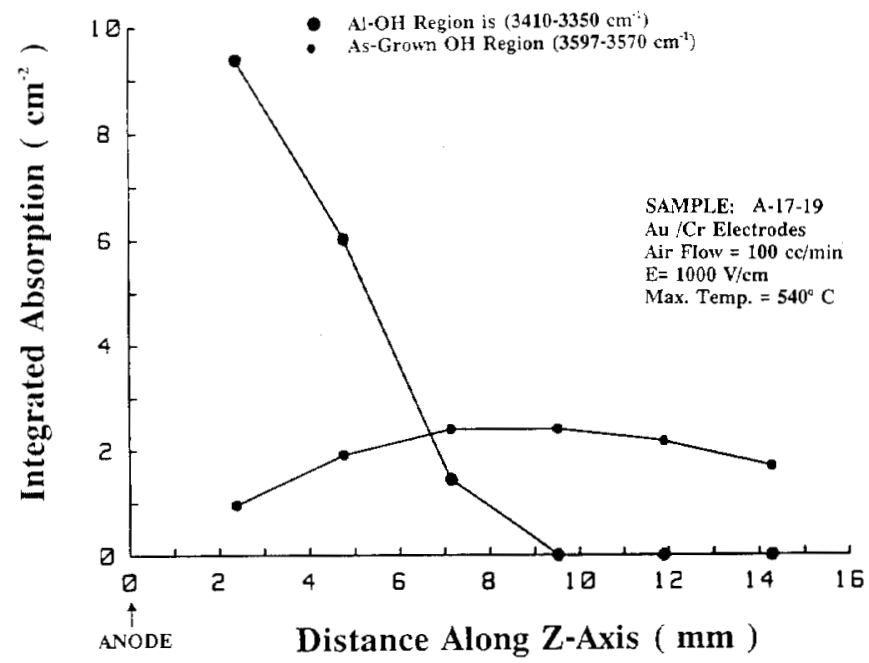

Fig. 1. Integrated infrared absorption $\left(300^{\circ} \mathrm{K}\right)$ of a series of spectral scans. The IR beam was unpolarized and in the $X$-direction. The Al-OH band was nonuniform along the $Z$-axis. The as-grown $O H$ band is depleted in the region near the anode.

centers when $\mathrm{Au}-\mathrm{Cr}, \mathrm{V}$, and $\mathrm{Al}$ electrodes are used and metal-silicide compounds develop to inhibit the metalquartz interfacial (lateral) diffusion of $\mathrm{H}$ species prior to the indiffusion of hydrogen [4]. During sweeping, aluminum compensated by electron-holes $\left(\mathrm{Al}-\mathbf{h}^{+}\right)$develops much more slowly than aluminum compensated by hydrogen (Al-OH) [6]. The $3585 \mathrm{~cm}^{-1}$ band due to as-grown $\mathrm{OH}$ also is depleted, especially in the anode region, because the crystal uses as-grown $\mathrm{OH}$ as an internal source of hydrogen for compensation of Al impurities [6]. This leads to nonuniform sweeping along the $Z$-axis similar to that found using vacuum sweeping [3].

The use of evaporated metallizations also results in metal diffusion into the quartz. The metal ions can couple to ultrasonic vibrations in quartz, leading to considerable increases in acoustic loss [7]. The movement of these impurities is influenced by the gradient of vibrational stress [8] and may contribute to long-term frequency shifts in bulk and SAW devices [9]. Suppression of electrode-metal indiffusion during sweeping can be achieved by reductions in the maximum sweeping temperature. reductions in sweeping electric field, reductions in surface damage through mechanical or chemical polishing of quartz surfaces prior to metallization, and the use of diffusion barrier films between the quartz and the metal electrode [10], 
[13]. Most of these methods are costly to implement and result in only partial suppression of electrode-metal diffusion.

The use of metal-foil electrodes is not an obvious remedy for these problems. Metal-foil electrodes are inefficient because they are not in continuous contact with the quartz, but only in contact with discrete areas. The result of this discrete contact is that ions and electrons will be restricted in their flow to points of anode-quartz-water vapor or hydrogen contact. Areas of the quartz not close to direct electrical contact are subject to reduced indiffusion of hydrogen [10].

All of these effects have been observed using both high and lower quality quartz. However, the effects are observed more easily when lower quality quartz is swept [10].

The basis for this research was to increase our understanding of: 1) the mechanism for void formation before and during sweeping that leads to nonuniform $\mathrm{H}$ sweeping; 2 ) the conditions that restrict $\mathrm{H}$ introduction and allow nonuniformities to develop; and 3 ) the techniques and electrode types available to circumvent the restriction of uniform hydrogen indiffusion.

\section{EXPERIMENTAL METHODS}

Most samples of cultured quartz used in this investigation were obtained from one source (supplier $A$ ). The samples usea in the $\mathrm{Y}-\mathrm{Ba}-\mathrm{Cu}-\mathrm{O}$ study were obtained from a different source (supplier $D$ ). The samples, designated A-17-19 and D-74V7, were of lower quality and had similar $Q_{\mathrm{IR}}(3500)$ of 1.2 and 1.3 million, respectively. Samples of (A) quartz were lumbered into $Y$-bars after seed removal [11]. (D) samples were purchased as SC-bars. The Z-surfaces of each bar type were lapped, polished, and cleaned as outlined previously [4], [12].

For electrodes, evaporated $\mathrm{Au}-\mathrm{Cr}$ and $\mathrm{Ag}$ metallizations were applied to the polished and cleaned $Z$-surfaces of the lumbered $Y$-bars. Ag metallizations were used because of the well known migration of $\mathrm{Ag}$ into quartz during high-temperature processing. In some cases, open regions (stripes) were photolithographically etched into $\mathrm{Au}-$ Cr films (anode regions). Temeprature-ramped sweeping [13] (maximum temperature $537^{\circ} \mathrm{C}$ ) was carried out in an atmosphere of flowing laboratory air (flow rate $=100$ $\mathrm{cc} / \mathrm{min}$ ). An electric field of $1000 \mathrm{~V} / \mathrm{cm}$ was used in all experiments.

Films of $\mathrm{Y}-\mathrm{Ba}-\mathrm{Cu}-\mathrm{O}$ were grown by magnetron sputtering from a single stoichiometric $\mathrm{YBa}_{2} \mathrm{Cu}_{3} \mathrm{O}_{7}$ target. The films were grown at room temperature in flowing Argon (flow rate $=35 \mathrm{cc} / \mathrm{min}$ ) on the $Z$-surfaces of the quartz $Y$-bar substrates [14]. The films were annealed, in flowing-air atmosphere, as part of the temperature-ramped sweeping process (maximum temperature $=500^{\circ} \mathrm{C}$ ). $\mathrm{X}$-ray diffraction was used to study film crystallinity before and after sweeping. Rutherford backscattering spectroscopy (RBS) [5] was used to evaluate the possible diffusion into the quartz of the electrode constituents.
A Perkin-Elmer model 1760 Fourier transform infrared spectrophotometer (FTIR) was used to obtain room-temperature $\mathrm{OH}$-vibrational spectra. Optical microscopic techniques were used to study voided electrode regions and to image interior features of the swept bars. Scanning electron microscopic (SEM) techniques were used to study the microstructure of metallized surfaces.

\section{EXPERIMENTAL OBSERVATIONS}

Air-sweeping nonuniformities have been found to be related to electrode effects [4], [10]. Microscopic examination of $\mathrm{Au}-\mathrm{Cr}$ anode surfaces after sweeping reveals the formation of numerous voided areas. In some instances, it is clear that the voids in the electrodes are surrounded by thicker metal regions (see Fig. 2). When voiding occurs the color centers are bleached by the indiffusion of hydrogen. If voiding is extensive, formation of Al-OH predominates and sweeping is uniform. If the voiding and interfacial diffusion of hydrogen is inhibited, e.g., by the formation of $\mathrm{Cr}$-silicide compounds [4], [10], then color centers develop and the sweeping is nonuniform.

Color center development was observed visually when lower quality quartz was swept [10]. The coloration can be detected, using magnification, by the apparent lightbrown coloration of inclusions, when high quality quartz is swept. Alternatively, the detection of weak color-center absorption may be accomplished using visible lasers as sources [15].

When $\mathrm{Au}-\mathrm{Cr}$ electrodes were partially immersion overplated with gold, unbleached color-center regions (see Fig. 3) could be related to the particle size of the gold anode above the unbleached region. In the unbleached regions, the particle size was small. In the adjacent (bleached) regions the particle size was about ten times larger (see Fig. 4). Voided areas were only found in the large particle size region. The smaller particle size regions were unintentionally created during the overplating procedure. Overplating was used to increase the metallization thickness to allow-parallel-gap welding of goldplated molybdenum lead-in ribbon to the metallization. The smaller particle size regions coincided with the meniscus region of the partially immersed cathode (for the purpose of overplating).

Both welded and pressure contact areas of metal electrodes have been observed to void extensively, leading to increased $\mathbf{H}$ indiffusion. Regions beneath welded contact areas on $\mathrm{Au}-\mathrm{Cr}$ metallizations showed nearly complete bleaching of color centers (see Fig. 5(a)). The welded contact areas were found to contain a very high density of tiny openings (see Fig. 5(b)). Similarly, when Ag electrodes were used and the contact straps were pressed to the Ag surface, extensive voiding was observed in the contact region. In this case, nonuniform sweeping was evidenced by large amounts of $\mathrm{Ag}$ indiffusion into the quartz, except in the region beneath the contact strap (see Fig. 6). Considerable differences were found in the IR 


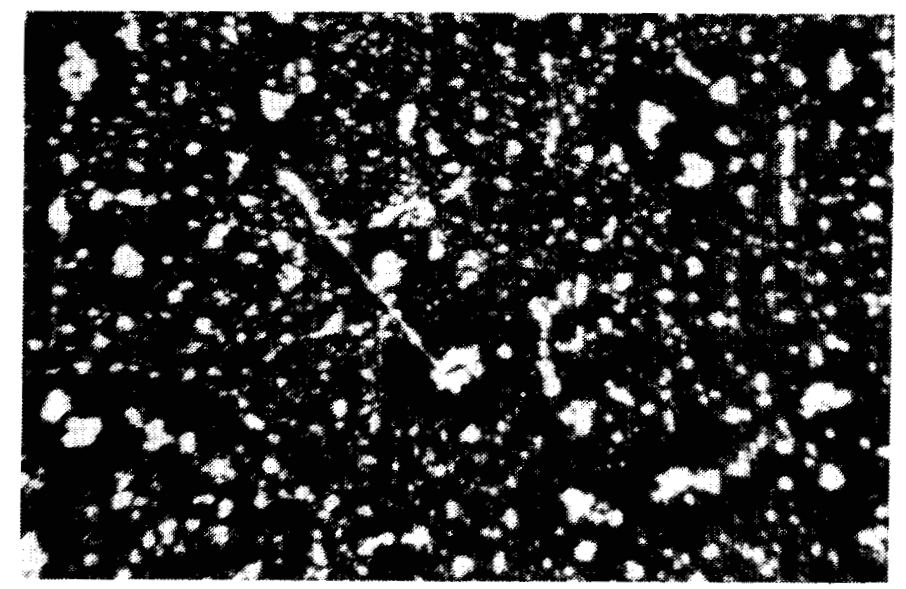

Fig. 2. Photonicrograph (at $200 \times$ ) of a $\mathrm{At}-\mathrm{Cr}$ anode surface after sweeping. Voided areas (white) are surrounded by thicker metal (dark) re gions. This porosity develops during sweeping.

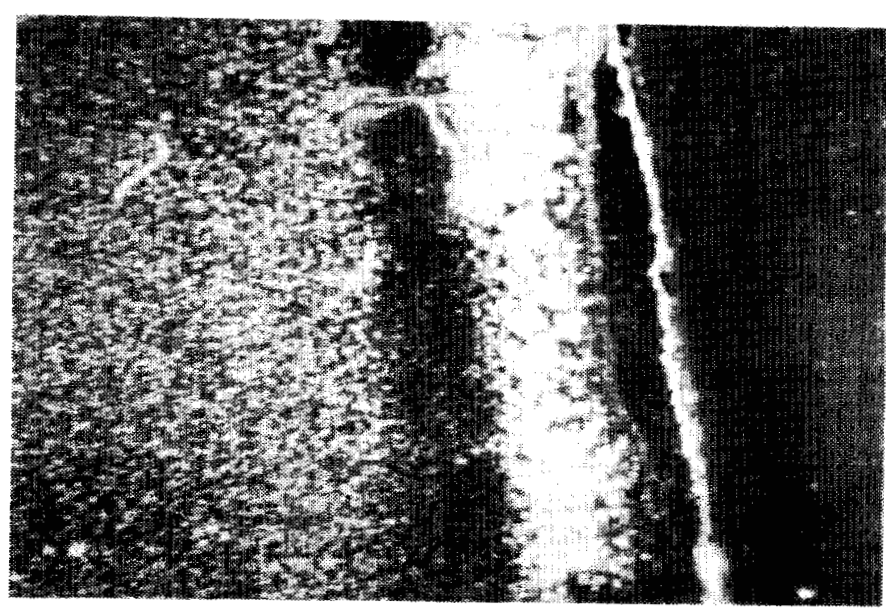

(a)



(b)

Fig. 3. (a) Photomicrograph of a Au-Cranode surface atter sweeping. This $Z$-axis view is through the quartz from the cathode side. Al! dark areas to the left of the crystal edge are color centers. This view shows two vertica (unbleached) color-centered areas, the one on the right coincides with a $35^{\circ}$ cut that terminates the bar. $(15 \times$.) (b) This $X$-axis view shows the two vertical (unbleached) color-center areas and the $35^{\circ}$ termination. (Anode area, $Z$-axis is vertical $)(7.5 \times)$

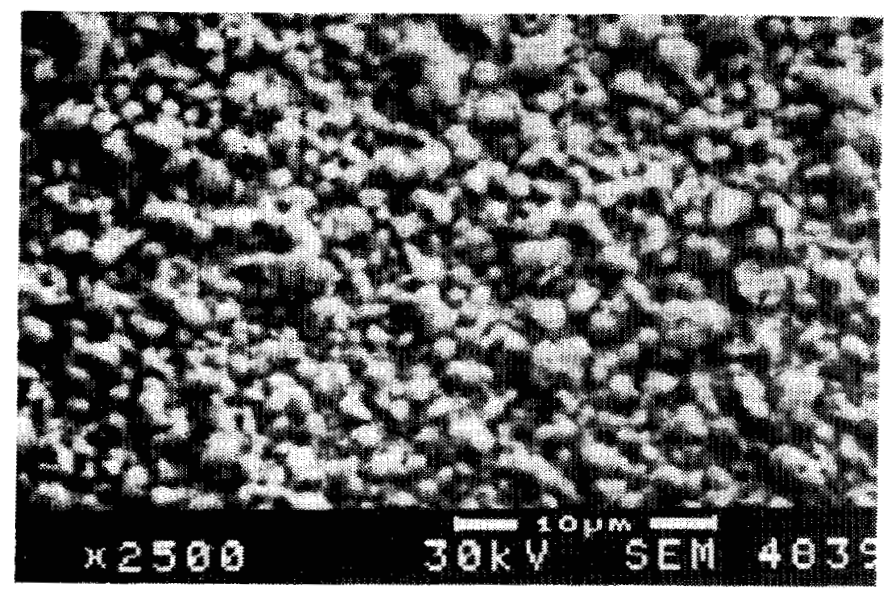

(a)

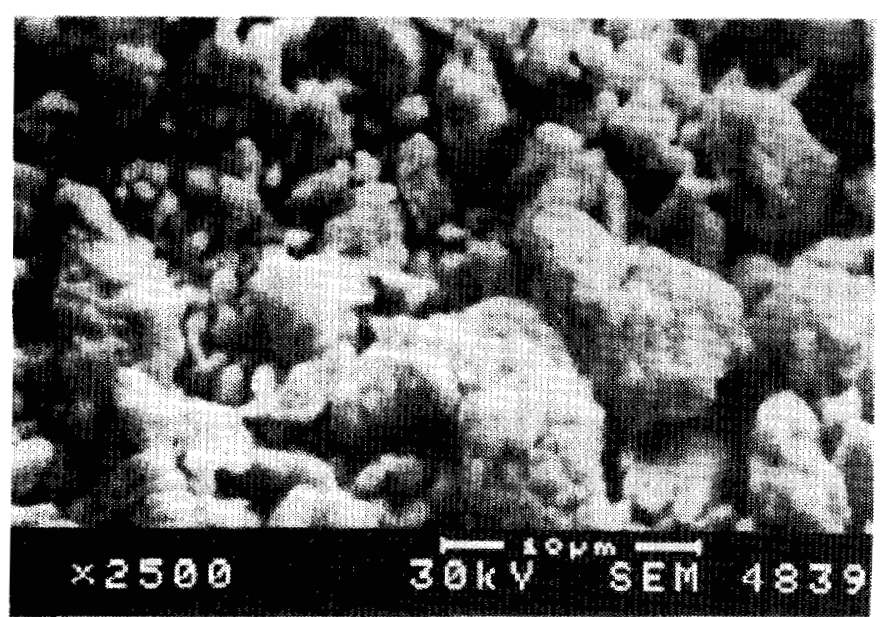

(b)

Fig. 4. SEM photograph (at $2500 \times$ ) of the $\mathrm{Au} / \mathrm{Cr}$ electrode (a) Above one of the unbleached color-center regions described in Fig. 3. The metal particle size is about $1 \mu \mathrm{M}$. (b) Adjacent electrode region that has developed porosity that has lead to $H$-diffusion and bleaching of color centers. The metal particle size is about $10 \mu \mathrm{M}$

absorption (due to $\mathrm{Al}-\mathrm{OH}$ ) of the clear region compared to the Ag-decorated regions (see Fig. 7).

\section{Discussion (Nonuniform SweEping)}

Quartz sweeping is affected by gas adsorption [4], [5] by the voided metal film which, in turn, is highly dependent on changes in the structure of the film during annealing [16]. These changes occur when sweeping is performed in controlled atmospheres, such as forming gas, as well as in air. The development of voids using air sweeping and $\mathrm{Au}-\mathrm{Cr}$ electrodes is probably enhanced by the oxidation of $\mathrm{Cr}$. Chrome oxide nodules and ridges develop to relieve stress, providing a high density of mass transport paths [17]. This stess-relief transition could be related to the onset of void formation and the noticeable increase in $\mathrm{H}$ introduction above $400^{\circ} \mathrm{C}$ [4], [18].

Openings in metal-film electrodes can exist after evaporation of the metal, resulting from surface contamination and probably stress voiding. The existence of internal 

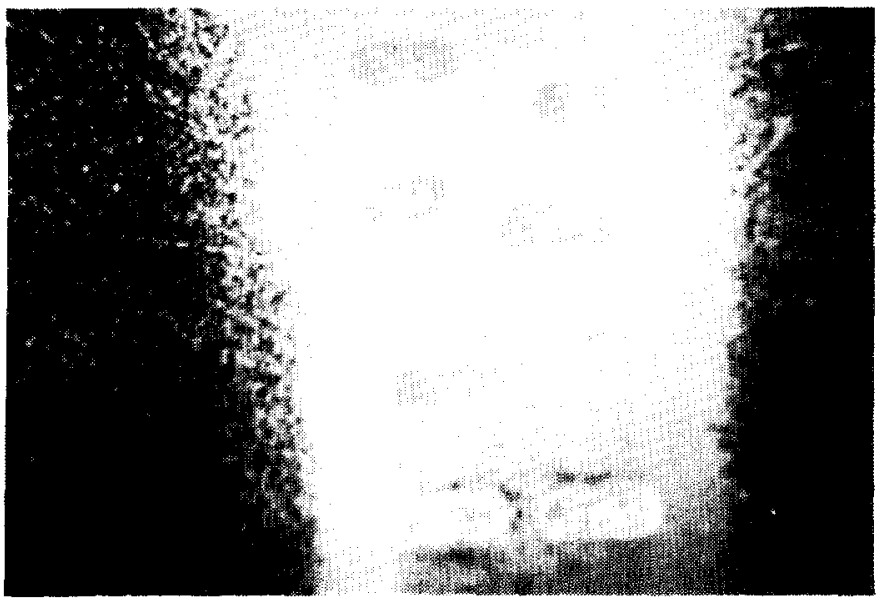

(a)

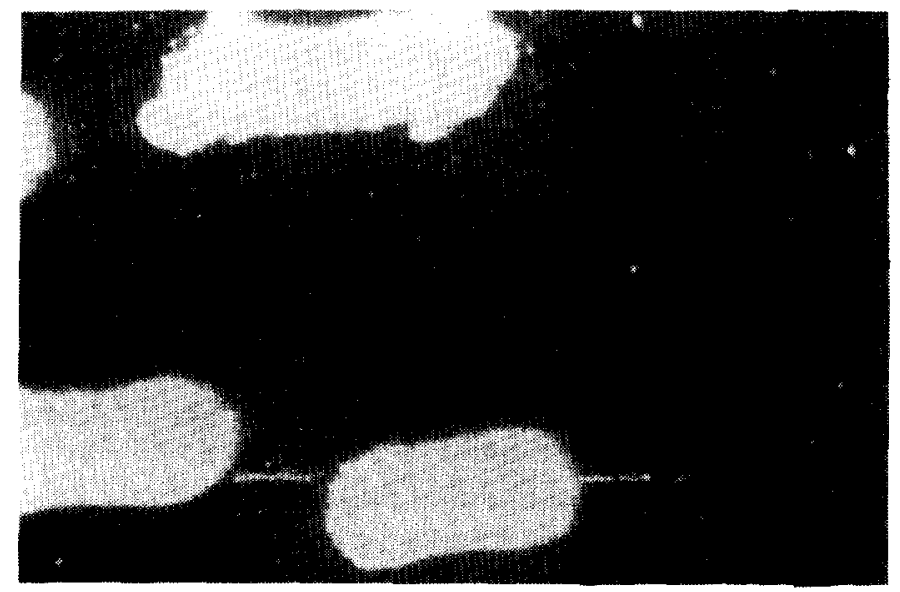

(b)

Fig. 5. Photomicrograph (at $16.5 \times$ ) of a $\mathrm{Au}-\mathrm{Cr}$ anode surface after sweeping ( $Z$-axis views). (a) This view (through the quartz from the cathode side), reveals color centers (dark areas). The light vertical band marks the area where a gold-plated molybdenum ribbon was welded to the electrode. This area shows complete bleaching of color centers. When the ribbon was peeled back. metal under the weld spots adhered to the ribbon, exposing several open-quartz areas. (b) The same view (at $37.5 \times$ ) as in (a) using backlighting to reveal porosity. The contact area contains a high density of tiny openings. The noncontact area to the right has fewer and larger openings.

stesses in films deposited on a substrate is well known. Thermal stresses result from a difference in the thermal expansion coefficients of the film and the substrate. Intrinsic stresses also exist, arising from impurities in the film and structural modifications occurring during film growth, in amorphous to crystalline transitions, and further growth of crystal films during high-temperture annealing processes.

Stresses in $\mathrm{Au}-\mathrm{Cr}$ and $\mathrm{Ag}$ films are tensile before annealing and the stresses average $2-3 \times 10^{9} \mathrm{dyn} / \mathrm{cm}^{2}$ for $\mathrm{Au}-\mathrm{Cr}$ and $0.2-0.75 \times 10^{4} \mathrm{dyn} / \mathrm{cm}^{2}$ for $\mathrm{Ag}[19,20]$. Annealing the film tends to expand the metal more than the substrate, resulting in a changeover at higher temperatures to compressive stress [16]. [21]. The film relieves stress by undergoing internal and surface modifications, such as particle growth, void formation, and surface dif-

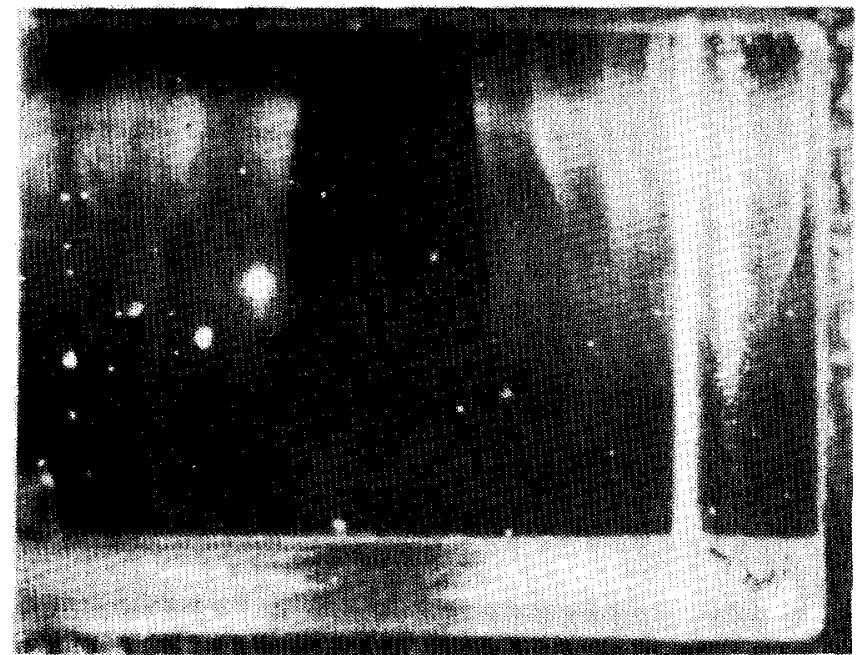

Fig. 6. Photomicrograph (at $3.75 \times$ ) of a quartz bar swept using Ag electrodes ( $Y$-axis view. $Z$-axis vertical). Silver has migrated into the bar from the anode (bottom) toward the cathode (top). Light-scattering bands, due to Ag-particles. are visible in the portion near the cathode. In the center of the bar, a clear region has developed. The clear region coincides with the area beneath the contact ribbon on the anode. The anode contact area appears to be depleted of silver because extensive porosity has developed.

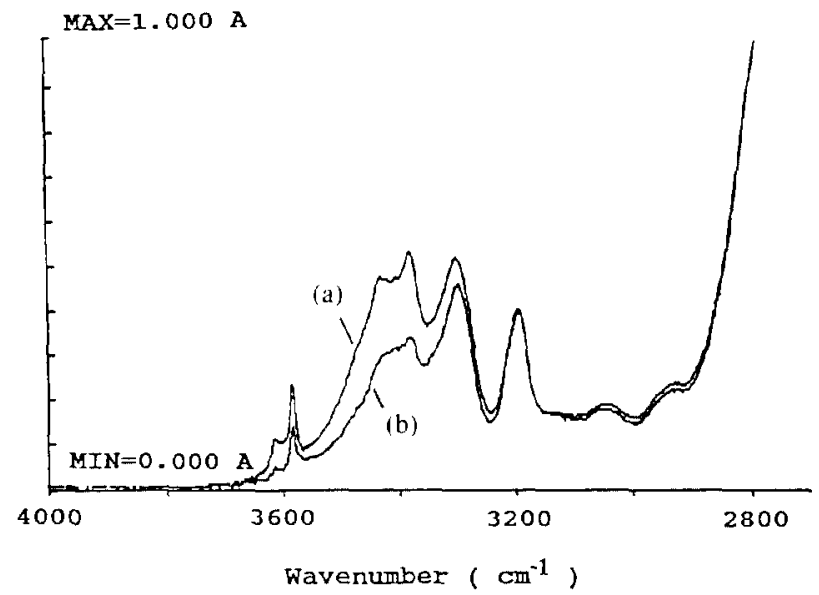

Fig. 7. Infrared absorption spectra of a $3.7-\mathrm{cm}$-thick sample of quart7 swept with Ag electrodes. The anode area was analyzed and the IR beam was along the $Y$-axis. (a) Clear region (no Ag decoration). (b) Ag-decorated region adjacent to the clear region.

fusion [21]. Since the atomic mobility is high, during the extended time and elevated temperature of sweeping, the film can relax by a stress-relief-vacancy-creep mechanism [22] causing formation of voids surrounded by thicker metal areas (see Fig. 2). Analysis of self diffusion under such conditions is extremely complicated and depends on vacancy source and sink geometry.

When $\mathrm{Au}-\mathrm{Cu}$ stripe electrodes were used, it was noticed that edge voiding occurred on thinner stripes $(25 \mu \mathrm{M}$ width). (See Fig. 8). Others have reported that large stresses concentrate along the edges of narrow-width metal stripes [23]. The fact that metal voids form predominantly along the narrow metal stripe edges, where stresses are expected to be greatest, suggests that a stress-induced 

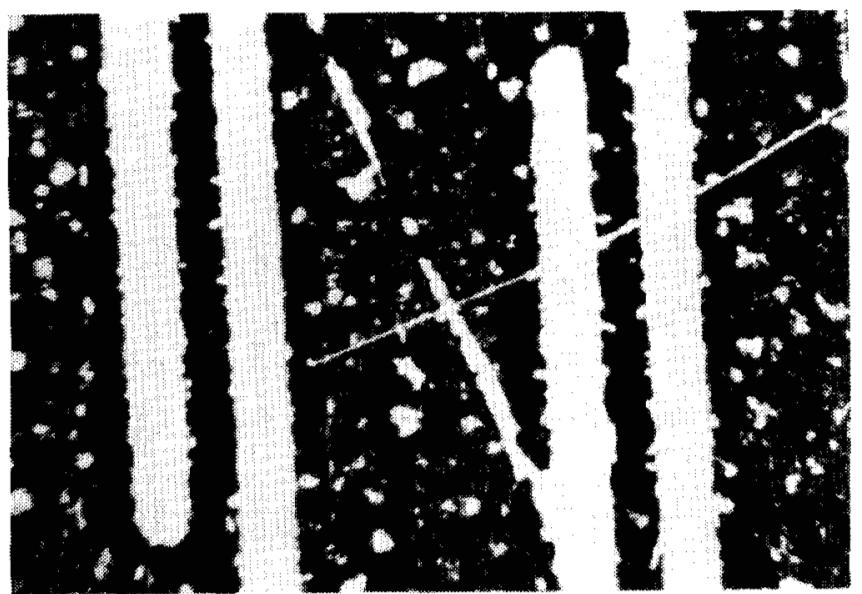

Fig. 8. Photomicrograph (at $200 \times$ ) of a $\mathrm{Au} / \mathrm{Cr}$ striped anode, backlighted to reveal voids. The dark stripes are metal, the white stripes are quartz. The thin $(25 \mu \mathrm{M})$ metal stripes are only voided at their edges.

mechanism is involved in the nucleation of voids in metal films to effect $\mathrm{H}$ sweeping.

The creation of voids beneath the welded or pressure contact areas could result from the combination of a simple load on the metal (applied compressive stress) and the intrinsic tensile stress of the film. It is well known that when tensile and compressive stresses coexist in metal films, vacancy diffusion can occur from grain boundaries in tension to boundaries in compresion [22] causing metal voids at elevated temperatures $[24]$. The high density of tiny voids in these regions is an indication of higher initial stress and subsequent reduction of surface area and stress relaxation upon annealing at the sweeping temperature [25].

\section{DisCUSSION (UNIFORM SWEEPING)}

\section{Au/Cr Films Containing Stripe Openings}

Since stress-induced surface migration of metal to create sufficient voids for uniform sweeping is difficult to control, periodic openings (stripes) were etched in $\mathrm{Au}-\mathrm{Cr}$ electrodes. The openings provided sufficient electrodequartz-water vapor (three-phase) regions to achieve uniform $\mathrm{H}$ indiffusion during sweeping (see Fig. 9). A photomicrograph of the electrode containing stripe openings is given in Fig. 10.

The metal-stripe width was designed to be less than twice the apparent $\mathrm{Au}-\mathrm{Cr}$-quartz interfacial $\mathrm{H}$ diffusion length found during our sweeping process. The interfacial $\mathrm{H}$-diffusivity for $\mathrm{Au}-\mathrm{Cr}$ electrodes was previously determined to be approximately $7 \times 10^{-9} \mathrm{~cm}^{2} / \mathrm{s}[4]$. Since we know that hydrogen diffuses into quartz at temperatures as low as $400^{\circ} \mathrm{C}$ (using $\mathrm{Au}-\mathrm{Cr}$ electrodes) [18] and our sweeping process is above this temperature for 36 hours, we can easily calculate the radius of the interfacially diffused area to be $0.03 \mathrm{~cm} \mathrm{[4],} \mathrm{[10].} \mathrm{The} \mathrm{metal} \mathrm{stripe} \mathrm{width}$ should be less than twice this radius (since hydrogen can diffuse inward interfacially from either stripe edge).

Hydrogen has been found to diffuse into the quartz from

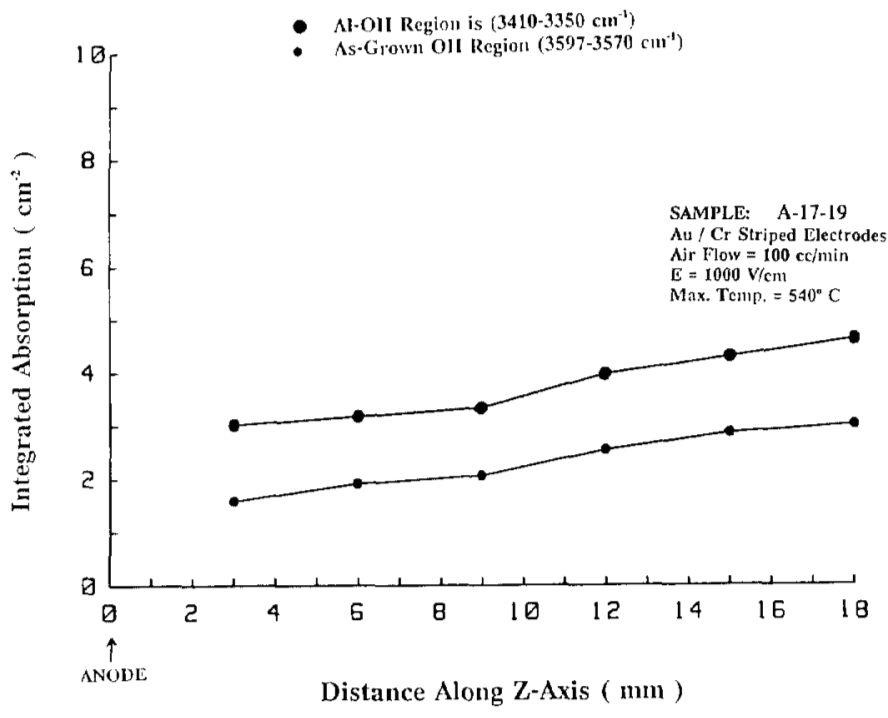

Fig. 9. The integrated infrared absorption $\left(300^{\circ} \mathrm{K}\right)$ of a series of spcetral scans (similar to Fig. 1) using Au/Cr striped electrodes. Both as-grown $\mathrm{OH}$ and $\mathrm{Al}-\mathrm{OH}$ bands are fairly uniform, increasing toward the cathode (seed) side of the bar.

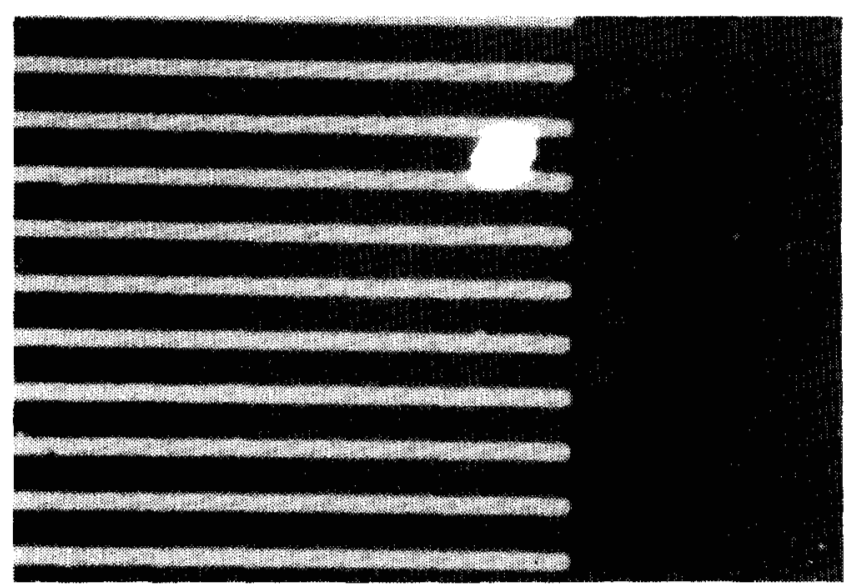

Fig. 10. Photomicrograph (at $26.5 \times$ ) of a striped Au-Cr anode surface after sweeping. The metal stripe width is $130 \mu \mathrm{M}$. the open quartz stripe width is $65 \mu \mathrm{M}$. Color centers were found to develop beneath the electrode area not striped leading to nonuniform $H$ introduction.

the open regions between the metal stripes. Hydrogen indiffusion in regions adjacent to a Au-Cr boundary was previously reported and discussed in $[10\rfloor$ (see $[10$, Fig. 13]). Since the $\mathrm{H}$ introduction region of open-quartz surface was found to be approximately $0.06 \mathrm{~cm}$ wide [4], [10], the open-stripe width should be less than $0.06 \mathrm{~cm}$ to ensure uniform sweeping.

\section{$\mathrm{Y}-\mathrm{Ba}-\mathrm{Cu}-\mathrm{O}$ Films}

Under the deposition and annealing conditions used here, the $\mathrm{Y}-\mathrm{Ba}-\mathrm{Cu}-\mathrm{O}$ films are amorphous and remain amorphous if the annealing temperture remains at or below $500^{\circ} \mathrm{C}$ [26]. The $1.75-\mu$ m-thick films were translucent and copper colored. The amorphous to cyrstalline transition begins above $500^{\circ} \mathrm{C}$ and annealing above $550^{\circ}$ 


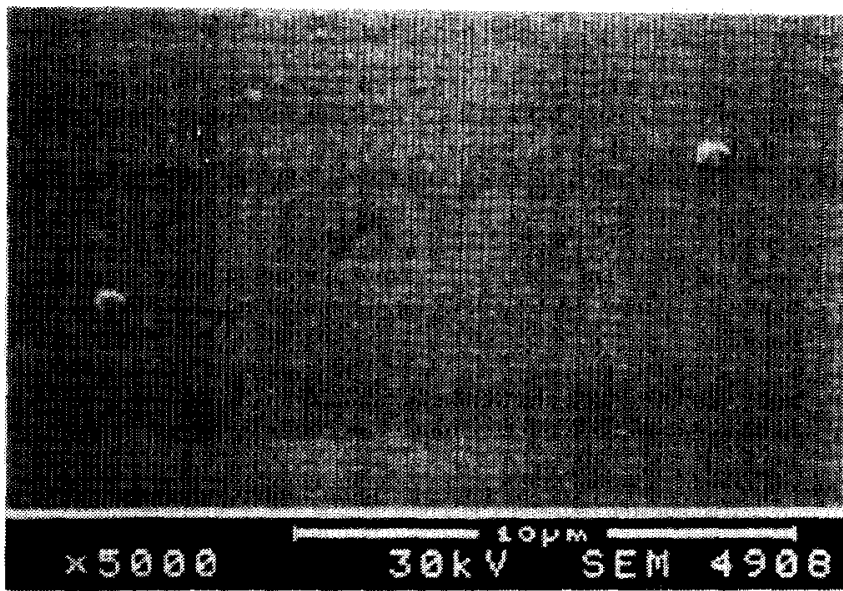

Fig. 11. SEM photograph of a $\mathrm{Y}-\mathrm{Ba}-\mathrm{Cu}-\mathrm{O}$ film electrode on quartz lafter sweeping). Voiding of the film was not detected using magnifications as high as $5000 \times$

C causes grain growth, voiding, and tearing of the films [25]. However, sweeping at temperatures at or below $500^{\circ} \mathrm{C}$ ensures that the film will remain amorphous. We have not detected any voiding or tearing of the films at sweeping temperatures at or below $500^{\circ} \mathrm{C}$ (see Fig. 11).

Since uniform indiffusion of hydrogen, to form $\mathrm{Al}-\mathrm{OH}$, was observed without any visible appearance of electronhole compensation (color centers) of Al (see Fig. 12), it was assumed that hydrogen, from the water vapor in the flowing-air atmosphere, had diffused through the film. Therefore, voiding of the electrode and interfacial diffusion of hydrogen, necessary in the case of $\mathrm{Au}-\mathrm{Cr}$ electrodes (and a source of nonuniform sweeping) is not required for the $\mathrm{Y}-\mathrm{Ba}-\mathrm{Cu}-\mathrm{O}$ electrodes. It is known that both oxygen and hydrogen readily diffuse into the $\mathrm{Y}-\mathrm{Ba}-$ $\mathrm{Cu}-\mathrm{O}$ crystalline phase [27] and that $\mathrm{YBa}_{2} \mathrm{Cu}_{3} \mathrm{O}_{7}$ in powdered crystalline form reacts very strongly with water [28].

Not much is known about the amorphous phase of $\mathrm{Y}-\mathrm{Ba}-\mathrm{Cu}-\mathrm{O}$, but it is suspected that films deposited at room temperature without a reactive oxygen atmosphere will be subject to hydrolysis [29]. In fact, an $\mathrm{H}-\mathrm{Y}$ ratio of 0.8 for the amorphous phase has been reported [30]. Reilly [31] showed that when hydrogen is reacted with $\mathrm{Y}-\mathrm{Ba}-\mathrm{Cu}-\mathrm{O}$, the hydrogen is coordinated primarily with $\mathrm{Cu}$ as an interstitial hydride. Since these hydrides decompose at $250^{\circ} \mathrm{C}$, hydrogen would be expected to easily diffuse through the film at the higher sweeping temperatures. A more recent simulation of RBS energies has revealed that $\mathrm{Cu}$ diffusion into the quartz may be indicated (see Fig. 13) in contrast to a previous report [32]. The indiffusion of copper must be limited, since no colloidal decoration of dislocations or haze was observed using light scattering microscopy [13].

Because the films remain amorphous during the sweeping process, they experience little or no stress-relief voiding associated with amorphous to crystalline transitions and further grain growth of metal crystal. For these rea-

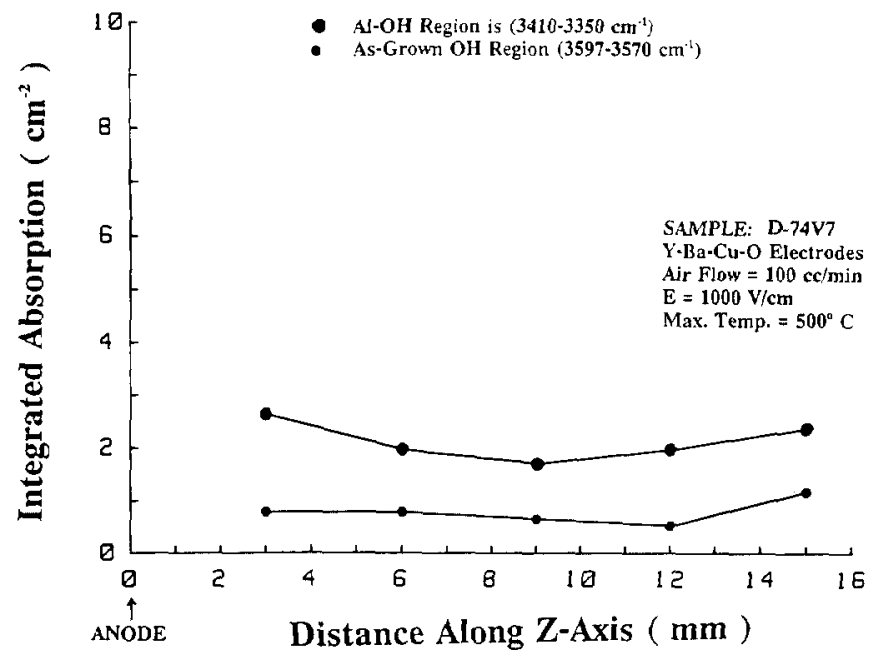

Fig. 12. The integrated infrared absorption $\left(300^{\circ} \mathrm{K}\right)$ of a series of spectral scans (similar to Fig. 1), using $\mathrm{Y}-\mathrm{Ba}-\mathrm{Cu}-\mathrm{O}$ electrodes. Both as-grown $\mathrm{OH}$ and $\mathrm{Al}-\mathrm{OH}$ bands are uniform across the bar.

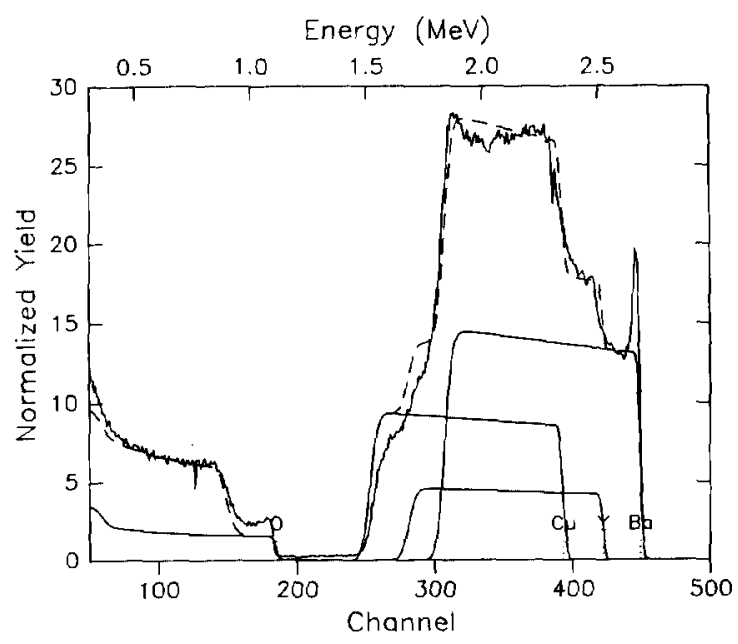

Fig. 13. RBS data for a $\mathrm{Y}-\mathrm{Ba}-\mathrm{Cu}-\mathrm{O}$ film on quartz (after sweeping). The individual simulations (solid lines) and cumulative (dashed line) are based on a $1.75-\mu \mathrm{M}$-thick film having $\mathrm{Y}_{1,3} \mathrm{Ba}_{2} \mathrm{Cu}_{4.8} \mathrm{O}_{12}$ stoichiometry (normalized to $\mathrm{Ba}_{2}$ ). Diffusion of $\mathrm{Cu}$ into the quartz interface is indicated by the degree of nonsuperposition of the data curve on the simulated Cu curve in the region $1.5-1.7 \mathrm{MeV}$. The simulations include beam straggling near the metal/quartz interface.

sons, $\mathrm{Y}-\mathrm{Ba}-\mathrm{Cu}-\mathrm{O}$ electrodes maintain uniform adherence to the quartz even after temperature cycling and prolonged high-temperature annealing encountered during the sweeping process. The film adherence is probably due to the formation of barium oxides and silicates, since copper has been reported as not interacting with $\mathrm{SiO}_{2}$ [33]. Use of $\mathrm{Y}-\mathrm{Ba}-\mathrm{Cu}-\mathrm{O}$ films as sweeping electrodes results in adequate hydrogen diffusion through the film to enable $\mathbf{H}$ penetration of the quartz and $\mathrm{H}$ replacement of alkali at Al impurity sites, in the lattice. Uniform replacement of alkali with hydrogen, across the sample bar (from anode to cathode), was found when these electrodes were used. Uniform sweeping with respect to areal contact is also maintained because the films allow diffusion of hydrogen 
and do not require openings or voids to create three-phase regions (regions where water vapor/hydrogen, quartz, and electrode coexist).

\section{CONCLUSION}

Stress-induced voiding of evaporated metal electrodes normally provides openings (electrode-quartz-water vapor regions) that allow the indiffusion of hydrogen for sweeping. The voiding is influenced by metal particle size and the application of compressive stresses.

Since the extensive stress-induced voiding necessary for uniform sweeping is difficult to control, sufficient open metal-electrode regions can be created artificially to ensure uniform $\mathrm{H}$-sweeping.

Uniform $\mathrm{H}$ sweeping also can be achieved by using $\mathrm{Y}-\mathrm{Ba}-\mathrm{Cu}-\mathrm{O}$ electrodes that permit the diffusion of hydrogen without the need for electrode porosity.

Finally, the electrode properties noted here may be of interest for resonator applications. The extreme temperature and electric field involved in sweeping can be considered an accelerated aging test for the stability of electrode films. The stress-induced void formation observed here using $\mathrm{Au}-\mathrm{Cr}$ films, compared to the excellent stability of the $\mathrm{Y}-\mathrm{Ba}-\mathrm{Cu}-\mathrm{O}$ films, suggests that the use of amorphous electrically conducting oxide film electrodes may yield resonant devices with improved stability.

\section{ACKNOWLEDGMENT}

The authors thank Mr. William Washington for preparation of quartz samples, Dr. George McLane and Mr. Melvin Wade for metallizations, Ms. Mary Saunders and Mr. Armand Balekdjian for the photolithographic work, Dr. Robert Pffefer and Mr. Chris Wrenn for the RBS work, and Mr. Donald Eckart for the SEM and X-ray diffraction work.

\section{REFERENCES}

[1] B. R. Capone, A. Kahan, R. N. Brown. and J. R. Buckwalter. "Quartz crystal radiation effects," IEEE Trans. Nucl. Sci., vol NS-17. pp. 217-221, 1970.

[2] J. J. Martin, "Electrodiffusion (Sweeping) of ions in quartz-A review." IEEE Trans. Ultason. Ferroelec. Freq. Cont. vol. 35, pp. 288-296. 1988

[3] H. G. Lipson, A. Kahan, and J. O'Connor, "Aluminum and hydrox ide defect centers in vacuum swept quartz." in Proc. 37th AFCS, 1983, pp. $169-176$

14] J. G. Gualtieri, L. Calderon, and R. T. Lareau. " Update on possible electrode mechanisms in the sweeping of alpha quartz, " in Proc. 43rd Annu. Freq. Cont. Symp. (AFCS). IEEE, 1989, pp. 509-516.

[5] J. G. Gualtieri, "Possible mechanisms for the introduction of hydrogen into alpha quartz during sweeping, " in Proc. 42nd AFCS, 1988. pp. 155-161.

16] G. B. Krefft, "Effects of high temperature electrolysis on the coloration characteristics and $\mathrm{OH}$-absorption bands in alpha quartz. " $\mathrm{Ra}$ diation Effects, vol. 26, pp. 249-259. 1975.

[7] R. K. Cook and R. G. Breckenridge, "Anelasticity of quartz. "Phys. Rev., vol. 92, pp. 1419-1423, 1953.

[8] R. R. Sharp and E. L. Pace, "Direct observation of impurity motion in quartz using the Raman effect," J. Phys. Chem. Solids, vol. 31 pp. 2275-2279, 1970.

[9] B. K. Sinha and S. Locke, "Thin film induced effects on the stability of SAW devices," IEEE Trans. Ultrason. Ferroclec. Freq. Contr. vol. 36, pp. 231-241, 1989.

[10] J. G. Gualtieri, R. T. Lareau, and D. W. Eckart, "Electrode effects in the sweeping of alpha quartz," IEEE Trans. Ultrason. Ferroclec: Freq. Contr., vol. 37, pp. 393-403, 1990.

[11] J. G. Gualtieri and J. R. Vig, "Sweeping and irradiation studies in quartz," in Proc. 38th Annu. Freq. Control Symp., IEEE May 1984, pp. $42-49$.

[12] J. G. Gualtieri and D. W. Eckart, "The influence of surface finish and metallization on electrode electromigration in alpha quartz during sweeping," in Proc. 40th. Annu. Freq. Contr. Symp. IEEE. May 1986, pp. $115-120$

[13] J. G. Gualtieri, "The influence of temperature and electric field on the etch-channel density in swept-cultured quartz." in Proc. $39 t h$ AFCS, 1985, pp. 247-254.

[14] G. McLane, R. Pffefer, W. Savin, C. Wrenn, "Triode magnetron sputtered superconducting $\mathrm{Y}-\mathrm{Ba}-\mathrm{Cu}-\mathrm{O}$ thin films," in Proc. Army Workshop on High T. Superconductors, May 23-25. 1989, Redstone Arsenal. AL. Doc\# GAC/AC PR-89-02. published by IIT Research Inst., $10 \mathrm{~W}$. 35th St., Chicago, IL 60616.

[15] H. G. Lipson, "Infrared and laser spectroscopic characterization of aluminum defects in cultured quartz," in Proc. 40th Amn. Freq. Contr Symp.. 1986, pp. 63-69.

[16] R. Aberman and R. Koch. "Internal stress of thin silver and gold films and its dependence on gas adsorption." Thin Solid Films, vol. 62, pp. 195-208, 1979

[17] D. J. Young and $M$. Cohen, "Oxidation behavior of chromium between $300^{\circ}$ and $600^{\circ} \mathrm{C}, " \mathrm{~J}$. Electrochem. Soc., vol. 124, pp. 769774. 1977.

[18] D. W. Hart, J. Frank. D. Smith, J. J. Martin, and J. G. Gualtieri, "A study of the electrodiffusion process in quartz, "Proc. 44th Ammu. Freq. Contr. Symp. 1990, pp. 222-227.

[19] K. L. Chopra, Thin Film Phenomend. New York: MeGraw-Hill, 1969. ch. V.

[20] E. Klokholm and B. S. Berry. "Intrinsic stress in evaporated metal films," J. Electrochem. Soc., vol. 115, no. 8, pp. 823-826, 1968.

[21] A. Christou and H. Day, "Structure and thermal stability of sputtered Au-Ta films," J. Appl. Phys., vol. 44, no. 8, pp. 3386-3393, 1973.

122] A. H. Cottrell, An Introduction to Metallurgy. New York: St. Martins Press. 1967. pp. 355-358 and p. 843.

[23] S. K. Groothius and W. H. Schroen, "Stress related failures causing open metallization." Proc. $25 \mathrm{~h}$ Int Reliability. Physics Symp.. (IRPS), pp. 1-8, 1987

[24] J. T. Yue. W. P. Funsten, and R. V. Taylor, "Stress induced voids in aluminum interconnects during IC processing. " in Proc. 23rd IRPS, 1985. pp. 126-137.

[25] B. Kebbai, C. Khan Malek, and F. R. Laden, "Stress and microstructure relationships in gold thin films, "Vactum, vol. 4l, nos. 4-6, pp. 1353-1355. 1990.

[26] S. I. Shah, "Annealing studies of $\mathrm{YBa}_{1} \mathrm{Cu}_{3} \mathrm{O}_{7}$, thin films," Appl. Phys. Lett., vol. 53, no. 7, pp. 612-614, 1988.

[27] H. Wiesmann, D. H. Chen, R. L. Sabatini, J. Hurst, J. Ochab, and M. W. Ruckman, "Effect of stoichiometry and post-annealing conditions on magnetron sputtered films of $\mathrm{YBa}_{2} \mathrm{Cu}_{3} \mathrm{O}_{7}$ on cubic zirconia," J. Appl. Phys., vol. 65, pp. 1644-1647, 1989.

[28] R. L. Barns and R. A. Laudise, "Stability of superconducting $\mathrm{YBa}_{2} \mathrm{Cu}_{3} \mathrm{O}_{7}$ in the presence of water," Appl. Phes. Lett., vol. 51, no. 17. pp. 1373-1375, 1987

[29] Private communication with Dr. H. Wiesmann, Dept. Appl. Sci., Brookhaven National Laboratory, Upton, NY 11973, Mar. 1990.

[30] V. V. Sinitsyn et al., "The influence of hydrogen on the superconducting ceramic $\mathrm{YBa}_{2} \mathrm{Cu}_{3} \mathrm{O}_{1}$ " Sol'. Phys. Solid State, vol. 31, no 12. pp. 2056-2060, Dec. 1989

[31] J. J. Reilly, M. Suenaga. J. R. Johnson. P. Thompson, and A, R Moodenbaugh, "Superconductivity in $\mathrm{H}_{4} \mathrm{YBa}_{2} \mathrm{Cu}_{3} \mathrm{O}_{7}$," Phys. Rev. B., vol. 36, no. 10 , pp. 5694-5697. 1987

[32] J. Gaultieri, J. Kosinski, and R. A. Murray, "Nonuniformities in the sweeping of quartz. " in Proc. 44th Annu. Freq. Contr. Symp., 1990. pp. 228-237.

[33] R. Pretorius, J. M. Harris, and M.-A. Nicolet. "Reaction of thin metal films with $\mathrm{SiO}_{2}$ substrates," Solid-State Electron.. vol. 21.pp $667-675,1975$. 


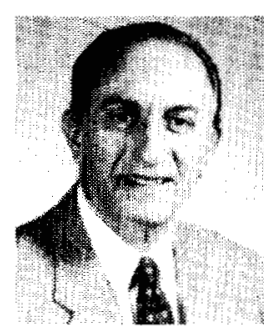

John G. Gualtieri (M'81-SM'91) was born on October 16, 1932 in Newark, NJ. He received a B.S. degree in physics and chemistry from Upsala College, East Orange, NJ in 1954, and an M.S. degree in physics from the University of Connecticut in 1956. From 1958 to 1972, he was on the staff of the Institute for Exploratory Research at Fort Monmouth, NJ. During this time, his work involved passivation of semiconductor surfaces, development of new concepts in bulk and surface bonding in crystals, research on spectroscopic properties of rare earth compounds, and development of narrowband infrared detectors.

From 1974 to 1978 , he was employed at the Combat Surveillance Target Acquisition Laboratory at Fort Monmouth. His responsibilities involved development of stoichiometric compound solid-state lasers for fiber optic and rangefinder/targer designator systems. In 1979 he joined the Electronics Technology and Devices Laboratory (ETDL), where his research interests have included the development of Berlinite for advanced acoustic wave devices, radiation sensitivity of quartz reasonators, and the sweeping of quartz for reduced radiation sensitivity and reduced etch-channel density. His recent research has emphasized the effects of electrodes on the sweeping of alpha quartz.

Mr. Gualtieri is a member of the SPIE and the EIA Quartz Material Subcommittee.

John A. Kosinski (A $86-\mathbf{M}^{\top} 88$ ), for a photograph and biography, please see page 66 of the January 1991 issue of this TRANisactions. 